RAD Conference Proceedings, vol. 3, pp. 220-224, 2018

ISSN 2466-4626 (online) | DOI: 10.21175/RadProc.2018.46

www.rad-proceedings.org

\title{
RADIATION HORMESIS IN THE LIGHT OF THE LAWS OF QUANTUM THERMODYNAMICS
}

\section{Yu.P. Chukova*}

\author{
The Moscow Society of Researchers of Nature, Krasnopresnenskiy Ecological Fund, Moscow, Russia
}

\begin{abstract}
Radioactivity is perceived as the most terrible danger by regular people. Radioactivity has always been studied in such aspect. Therefore, the occurrence of messages about the useful effects of a weak influence of radioactivity has caused counteraction and has generated the debate lasting till this moment. Thermodynamics is capable of bringing clarity to this problem. Else, in the 19th century, thermodynamics discovered two types of interactions of the system with the environment. In one case, the volume and entropy are constant in a system, and in the second one, the volume and temperature remain constant. The process in the second case is called an isothermal one and in the first case - a thermal one. Quantum thermodynamics was developed in the second half of the 2oth century for electromagnetic radiation. It was shown that isothermal processes take place at weak influence on the system, and the thermal ones - at strong influences. Let us pay attention to the fact that the logarithmic scale for the absorbed energy is used for isothermal processes, and the linear scale is used for thermal processes. The logarithmic scale allows to uncover what is hidden in the zero point of thermal processes. In the previous reports of the author at $R A D$ 2012, 2014, 2017 conferences, it was shown that quantum thermodynamics is valid for all three parts of radiation ( $\alpha$-, $\beta$ -,$\gamma$-radiation) and not only for $\gamma$-radiation. The application of the thermodynamic theory to hormesis effects allows us to provide a fresh insight on the essence of proceeding processes. For the experimenters who recorded a U-curve of a dose-effect dependence, it is useful to understand and remember that they study the identical answer of an organism which is a result of two fundamentally different processes: the left branch of the U-curve shows the end of the processes of a weak influence on an organism, and the right branch is the beginning of the effect of strong influences. Strong influences give a linear (or close to it) dose-effect dependence. They have been studied comprehensively and for a long time, and they are object of a hygienic standardization. Among the investigators studying strong influences, there is a different view on the threshold for a dangerous action: some consider dangerous even the smallest doses, and others reject any effects of doses below the threshold. Maybe they are excused by their ignorance of thermodynamics, especially if one is to consider that in thermodynamics there is no concept of harm. But if experimenters wish to deeply understand the essence of the processes they study, they should get acquainted with the general laws of quantum thermodynamics. Then, it would become clear to them why hormesis was found not only in radiobiology, but also in many other sciences. Hormesis is fixed by any experimenter working in a certain range of influences where the system changes the type of its answer to environmental influences (boundary of isothermal and thermal processes).
\end{abstract}

Key words: Efficiency of energy conversion, Wien region, chemistry hormesis, microwave bioeffects

\section{INTRODUCTION}

Norbert Wiener, founder of Cybernetics and theory of artificial intelligence, said: "Important studies are delayed due to the fact that in a given area known results that have become classics, they remain unknown in the adjacent field". These words of Wiener are most directly related to radiation hormesis because the scientists studying radiation hormesis do not know what has become a classic in thermodynamics. I will start with hormesis but then move on to thermodynamics.

\section{HORMESIS}

After discovering $\gamma$-radiation (A. Becquerel, 1896), their damaging effect was revealed very quickly. A stimulating effect was detected much later and it was less frequent. The term "hormesis" first appeared in scientific publications in 1942, when describing the stimulation of cell division and the growth of fungus under the influence of the antibiotic at low concentrations, while at higher concentrations the antibiotic had a depressing effect. This direction continues its successful development to this day.

Radioactivity (immediately after its discovery) attracted the attention of scientists because of its dangerous effects on the body. This aspect was the main in all research and created in the eyes of the population an image of the most dangerous effects. The stimulating effects of radioactivity were rare and inherently incomprehensible.

In 1980, Luckey T.D. published the book [1] in which he generalized the information of his predecessors and added to them his own experiments

*y.chukova2015@yandex.ru 
Yu.P. Chukova, Radiation hormesis and laws of quantum thermodynamics, RAD Conf. Proc., vol. 3, 2018, 220-224

on the stimulating effect of the low doses of ionizing radiation and introduced the term "radiation hormesis". The most interesting was a U-shaped hormesis. The discoverers of hormesis and their followers believe the phenomenon is unexplained, although it has long been understood and explained in thermodynamics.

\section{THERMODYNAMIC METHOD}

Thermodynamics originated (came into being) in the 19th century and has as its foundation the works of S. Carnot (1824), B. Clapeyron (1834), J. Mayer (1842 ), John Joule (1843), Helmholtz (1847), W. Thomson (Lord Kelvin, 1851) and R. Clausius (1851 and 1865).

In $1873-78$, Gibbs introduced four thermodynamic potentials: internal energy, enthalpy (heat content), Helmholtz free energy, free enthalpy (or Gibbs free energy). The study of these functions is the content of all the textbooks on thermodynamics, in which they are presented in exactly the same order as listed above. This sequence is historical: they appeared in the process of scientific cognition of the world in this order.

I reported on the quantum thermodynamics of irreversible isothermal processes under electromagnetic radiation at previous $\mathrm{RAD}$ conferences, and the results were published [2,3]. Therefore, now I will use only the final result of this theory.

First, a few words about the frequency range of electromagnetic radiation $\left(\mathrm{o}-10^{22} \mathrm{~Hz}\right)$. The whole of this range is divided into 7 parts by experimenters (extremely low frequencies, radiofrequencies, infra red radiation, ultraviolet, visible light, $\mathrm{X}$-rays, $\gamma$-radiation). This division is set by the equipment, which is used by scientists to produce radiation with different frequencies. Gamma radiation has quanta of $h v$ with the highest energy ( $v$ from $10^{20}$ to $10^{22} \mathrm{~Hz}$ ).

As for the theorists, they divide the full frequency range into two parts. Rather, it itself is divided into two parts, regardless of the desires of theoretical physicists. This is the Wien region and the Rayleigh-Jeans region. Experimenters do not use such terminology, but such division should be known to them if they have a higher education. This division-classical knowledge is from the end of the 19th century. Experimenters talk about long-wave radiation when they work in the RayleighJeans region, and about short-wave radiation if they work in the Wien region. For numerical features, they use the ratio of the quantum energy of thermal radiation (kT) and energy $h v$. In the Wien region, hv $>>\mathrm{kT}$, and in the Rayleigh-Jeans region, $\mathrm{h} v<<\mathrm{kT}$. Two different laws of efficiency of conversion of electromagnetic radiation energy into the Helmholtz free energy work in these two regions. This is the Weber-Fechner law in the Wien region [4] and the Devyatkov law in the Rayleigh-Jeans region [5]. They are presented in the lower part of Fig. 1, where $E_{v}$ is spectral density of absorbed power.

Since gamma radiation and X-rays belong to the Wien region, in the future we will consider this region. Moreover, one single function will be considered - the efficiency of conversion of electromagnetic radiation energy into the Helmholtz free energy (endergonic processes). In the lower right corner of Fig. 1, the solid line represents the thermodynamic limit of the conversion efficiency. The broken line gives a real efficiency in the conditions of linear irreversible process, and the dot-and-dash line is the real efficiency in the conditions of nonlinear irreversible processes.

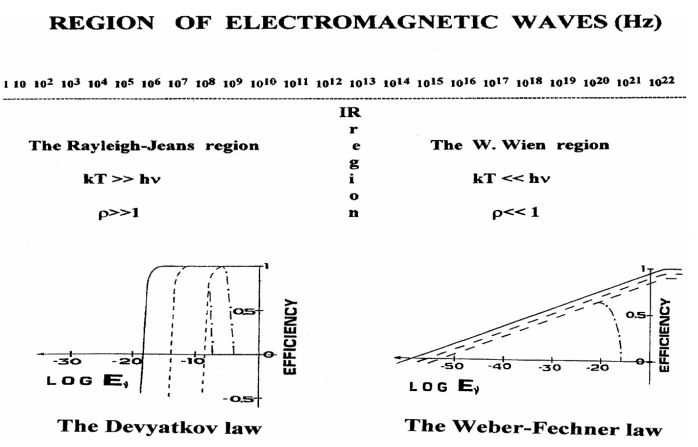

Figure 1. Plan for electromagnetic radiation

\section{CORRELATION WITH THE EXPERIMENT}

In Figure 2, the continuous line is a theoretical curve of the energy conversion efficiency under the conditions of linear and superlinear irreversibility of processes. It corresponds well with the experimental data of the most studied endergonic processes. The broken line marks the range of the human eye, the dotand-dash line gives the area of the photosynthesis of plants and algae. The points are the efficiency of solar cells. Photo movement protozoa exist throughout the solid curve. So, Fig. 2 shows that endergonic processes have a beginning and an end when the efficiency is zero.

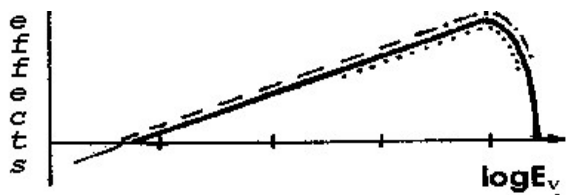

Figure 2. Correlation theory with the



Figure 3. Physical meaning of different parts of nonthermal process 
Yu.P. Chukova, Radiation hormesis and laws of quantum thermodynamics, RAD Conf. Proc., vol. 3, 2018, 220-224

Fig. 3 reveals the physical meaning of the different parts of the theoretical curve. The broken (dotted) line is the area of the increase of the Helmholtz free energy in conditions of linear irreversibility (endergonic isothermal processes). With a further increase in energy absorption, an isothermal is lost, but the process remains endergonic and nonthermal. The endergonic process ends in very weak heating conditions.

In connection with the title of the article, we will start with the end of the endergonic process. If the impact on the system continues to grow even after the endergonic process has ended, then there is a lack of response of the system. And thermal processes begin at the further increase of the external influence. They are presented in Fig.4 on the right side. So, we see the Ushaped response of the system in Fig.4.

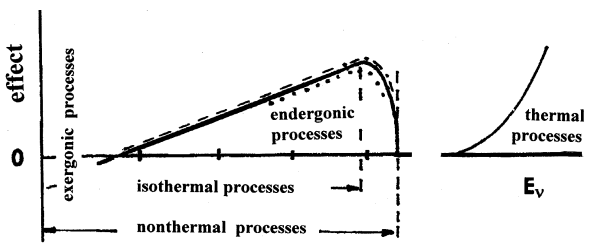

Figure 4. Isothermal and thermal processes

Here it is important to pay attention to the scale on the axes. On the ordinate axis, a linear scale is used, and on the abscissa axis in the area of endergonic processes - logarithmic scale, and in the field of thermal processes - linear one. Experimenters don't have that rigor. They present the results as they wish, but they are often forced to use a gap (or even two) on the abscissa axis.

\section{THE PHYSICAL MEANING OF THE U-SHAPED RESPONSE OF A SYSTEM}

If the experimenter does not go into the physical essence of the processes, he just states a U-shaped hormesis that he can not explain. A theorist, a specialist in thermodynamics experiments, on the contrary, can explain, knowing the essence. The essence of the case is shown in Fig.5. The left part of the figure refers to isothermal processes, where $\mathrm{T}=$ const, and the study of processes requires the consideration of thermodynamic potential of the Helmholtz free energy, and the right part of the figure characterizes the process in terms of entropy conservation ( $\mathrm{S}=$ const). This is a thermal process, which was studied by everyone who was engaged in thermodynamics, and everything is known about it. Therefore, I will not consider it.

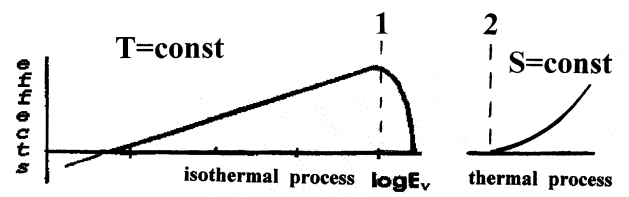

Figure 5. Thermodynamic zone of silence
The Fig. 5 is given in order to demonstrate the essence of the U-shaped response of a system and zone of silence. It is grandiose and of universal significance because it demonstrates the changing conditions of interaction between the system and the environment. For theorists working by deductive method, this is the starting point for all considerations. Experimenters, working by inductive methods, could hardly have such thoughts.

One of the formulations of the second law of thermodynamics is as follows: "It is impossible to convert heat into work without any changes in the surrounding bodies at the same time." What changes occur in the environment depends on the force of the impact on the system and the characteristics of the system that is affected.

Physicists have long known phase transitions. Moreover, physicists have shown that there are the first and the second kind. But they have nothing to do with what is presented in Fig.5. Phase transitions are related to the Gibbs free energy, or rather to the first and second derivatives of the Gibbs free energy. I didn't consider the Gibbs free energy.

Fig. 5 appeared as a result of consideration of thermodynamic potential of the Helmholtz free energy. That interval of the absence of the response of the system which is represented in Fig. 5 is associated with the change of system interaction with the environment. Different branches of the U-shaped hormesis represent something absolutely not similar to each other. Between them lies the interval of non-response (zone of silence of the system).

Experimentalists argued about whether there is a hormesis or not. Thermodynamics showed the cause of the existence of the U-shaped response. This opens the way to studying the interaction of a wide variety of systems with the environment. This line of research hormesis promises many interesting discoveries in the future.

In the U-shaped hormesis case, we have a more significant transition that determines the nature of the interaction of the system with the environment. It can be called the fundamental thermodynamic zone of silence, when a system goes from one type of interaction with the environment to another type.

The result of Fig. 5 was first published in 1998 in three editions simultaneously and subsequently published many times in Russian and English, including 4 books [4-7]. In total, there are about 30 publications of the author and several publications of foreign scientists.

Thermodynamics claims that changing the interaction with the environment is a general rule (law!) and should be observed in many processes. Universally!!!

Let's start with $\gamma$-radiation $\left({ }^{137} \mathrm{Cs}\right)$ of low intensity. Fig.6 illustrates the effect of the microviscosity of the lipid phase of the nuclear membranes (curve 1, light points) and the percentage of DNA binding (curve 2, black points) as a function of the acting dose. In the literature, a large number of similar results can be found. Fig. 6 has been chosen as the most carefully 
Yu.P. Chukova, Radiation hormesis and laws of quantum thermodynamics, RAD Conf. Proc., vol. 3, 2018, 220-224

performed experiment, described in detail in the literature [8].

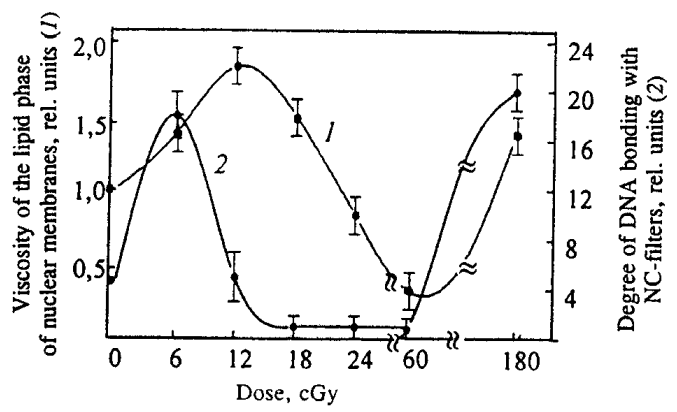

Figure 6. Dependence “dose-effect” in [8]

I draw attention to the 2 discontinuities on the abscissa axis that were necessary for the scientist in order to place all his results on a single graph using a linear scale for the dose.

\section{COMMONNESS OF THE U-SHAPED RESPONSE FOR THE SYSTEMS UNDER WEAK ELECTROMAGNETIC RADIATION [7]}

The fundamental thermodynamic zone of silence is valid not only for radiation hormesis. It is always valid when the system is exposed to long-wave electromagnetic radiation from the Rayleigh-Jeans region. In this area, the term "hormesis" has never been used. Moreover, it is not familiar to specialists in the field of microwave radiation. These specialists have long recorded the harmful effects of microwave radiation, and in 1973 found the therapeutic effect of three wavelengths $(4.9 \mathrm{~mm} ; 5.6 \mathrm{~mm}$ and $7.1 \mathrm{~mm})$. The overall picture for microwave radiation is represented in Fig. 7.

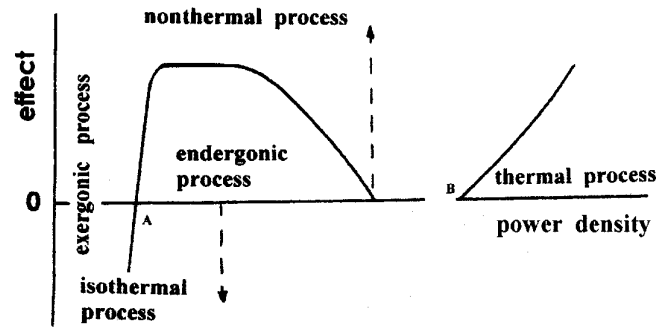

$$
A \approx 10 \mu W / \mathrm{cm}^{2} \quad B \approx 10 \mathrm{~mW} / \mathrm{cm}^{2}
$$

Figure 7. Thermodynamic zone of silence in Rayleigh-Jeans region (microwaves) [7]

Fig. 7 differs from figures $3-6$ in the form of the response curve of the system in the area of endoergic processes. This has a simple explanation and is connected with the essential difference between the Devyatkov law and the Weber-Fechner law (see Fig.1). About 100 publications of the author and 3 books are devoted to this subject [5-7]. The level of understanding of the phenomena in this area is much higher than in the field of radiation hormesis. Familiarity with these works that go beyond this publication will help professionals on radiation hormesis to become more successful in the study of radiation hormesis and to discover a new method for it research.

\section{COMMONNESS OF THE U-SHAPED RESPONSE OF THE SYSTEM UNDER ALL TYPES OF WEAK INFLUENCE ON IT}

Developed in the second half of the $20^{\text {th }}$ century, quantum thermodynamics is numerically tested on electromagnetic radiation, which includes only one component of radioactivity, namely gamma radiation. $\alpha$ - and $\beta$-particles are beyond the scope of this review.

However, in [3], it was shown that all conclusions of this theory are applicable to $\alpha$ - and $\beta$ - particles if the density of the filling of quantum states is lower than 1 (see Fig. 1). Moreover, the thermodynamic theory is valid for all kinds of effects on the system if the influence is subjugated to the statistics of BoseEinstein, Fermi-Dirac and Maxwell-Boltzmann, if the energy levels fulfill the condition of small filling of quantum states. This clearly demonstrates Fig.7 in the paper [3]. That is why a similar-shaped response of the system has been received in the field of chemistry and medicine.

The first experimental results refer to the end of the 19th century. Here I would like to acknowledge the work of the Nobel prize winner I. P. Pavlov who, studying the action of bromine, was watching the falling effect of the decreasing concentration of bromine, then the absence of the effect, and with a further decrease of the concentration of bromine, the effect occurred again.

A large number of measurements refer to the sphere of influence of chemical compounds on the growth and development of microorganisms, fungi, algae, plants and a wide variety of other biological objects.

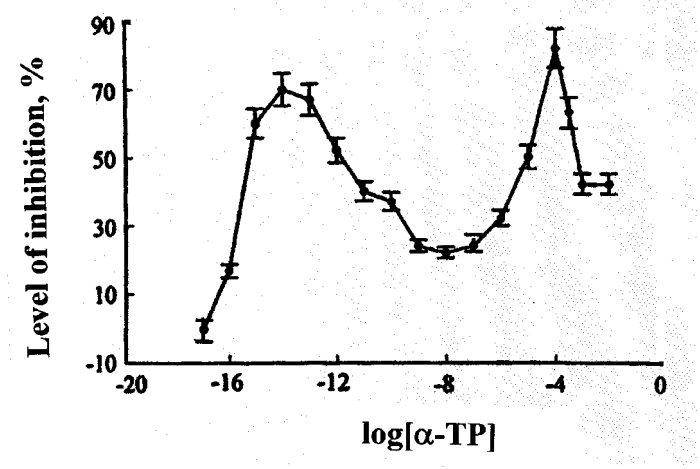

Figure 8. Dependence level of inhibition of proteinkinase $\mathrm{C}$ in [9]

Fig. 8 shows the effect of the natural antioxidant $\alpha$ tocopherol (vitamin E) on proteikinase C. Logarithm of concentration $\alpha$-tocopherol is on the abscissa axis, and 
Yu.P. Chukova, Radiation hormesis and laws of quantum thermodynamics, RAD Conf. Proc., vol. 3, 2018, 220-224

the degree of inhibition in percentage is on the ordinate axis [9].

The effect of $\alpha$-tocopherol on the activity of proteinkinase $\mathrm{C}$ is presented for a wide range of concentration changes $\left(10^{-17}-10^{-20} \mathrm{~mol} / \mathrm{liter}\right)$ in the experiments of the regulation of lipid peroxidation.

By the end of the twentieth century, the effects of the weak effects were studied on a large number of chemical compounds (more than 100). The extent of the area of used concentrations is large (from $10^{-10}$ to $10^{-20} \mathrm{~mol} / \mathrm{liter}$ ), while the length of the area of conventional therapeutic concentrations is from $10^{-4}$ to $10^{-6} \mathrm{~mol} /$ liter (the second maximum in Fig. 8).

\section{CONCLUSION}

The condition for the existence of life processes is low entropy and its increase by a linear law under the influence of external electromagnetic radiation allows life to realize their capabilities. Normal life is a linear entropy process, which, according to the second law of thermodynamics, pays quite a definite tribute for all its acts (both the one beneficial for the body and the harmful one). Life is not compatible with any extreme influences, but only with small and some moderate. The place of radiation hormesis in the overall structure of the natural sciences is considered in details in the book [10], which is now sold on the internet.

\section{REFERENCES}

1. T. D. Luckey, Hormesis with ionizing radiation, Boca Raton (FL), USA: CRC Press, 1980.

2. Yu. P. Chukova, "Fundamental laws of efficiency of isothermal processes under ionizing and non-ionizing electromagnetic radiation," in Proc. $1^{\text {st }}$ Int. Conf. Radiation and Applications in Various Fields of Research (RAD 2012), Niš, Serbia, 2012, pp. 351 - 353. Retrieved from: http://www.radconference.org/helper/download.php?file=../pdf/Proce edings\%20RAD\%202012.pdf; Retrieved on: Apr. 23, 2018

3. Yu. P. Chukova, "Radioactivity in the light of the fundamental law of physics," in Proc. $5^{\text {th }}$ Int. Conf. Radiation and Applications in Various Fields of Research (RAD 2017), Budva, Montenegro, 2017, pp. $260-264$.
Retrieved from: http://www.radproceedings.org/index.php?id $=2$ Retrieved on: Apr. 23, 2018

4. Ю. П. Чукова, Закон Вебера - Фехнера, Москва, Россия: ЗАО МП Гигиена, 2009. (Yu. P. Chukova, The Weber - Fechner law, Moscow, Russia: ZAO MP Gigiena, 2009.)

5. Ю. П. Чукова, Закон Девяткова (Эффективность нетеплового преобразования энергии длинноволнового электромагнитного излучения), Москва, Россия: Мегаполис, 2016. (Yu. P. Chukova, The Devyatkov law (Efficiency of nonthermal conversion of energy of long-wave electromagnetic radiation), Moscow, Russia: Megapolis, 2016.)

6. Yu. P. Chukova, Advances in nonequilibrium thermodynamics of the systems under electromagnetic radiation, Moscow, Russia: Khrizostom, 2001.

7. Ю.П. Чукова, Эффекты слабых воздействий. Термодинамический, экспериментальный (биологический $и$ медицинский), социальный, законодательный, международный и философский аспекты проблемы, Москва, Россия: Алес, 2002. (Yu. P. Chukova, Low-level influence effects. Thermodynamic, experimental (medical and biological), social, Legislative, international and philosophical aspects of problem, Moscow, Russia: Ales, 2002.)

8. E. B. Burlakova, "Features of the effect of ultra-low doses of biologically active materials and physical factors of low intensity," Mendeleev Chemistry Journal, vol. 43, no. 5, pp. 1-12, 1999.

9. Н. П. Пальмина, Е. Л. Мальцева, Е. И. Пынзарь, Е. Б. Бурлакова, "Модификация активности протеинкиназы C лигандами в сверхмалых концентрациях. Роль протеинкиназы С и её эффекторов в процессах пероксидного окисления," Журнал Российского химического общества им. Д.И.Менделеева, т. 43, но. 5, стр. 55 - 63, 1999. (N. P. Palmina, E. L. Malzeva, E. I. Pynzar, E. B. Burlakova, "Modification of activity of protein kinase $\mathrm{C}$ with ligands in ultra-small concentration. The role of protein kinase $\mathrm{C}$ and its effectors in the peroxide oxidation processes," Mendeleev Chemistry Journal vol. 43 , no. 5 , pp. $55-63$, 1999.)

10. Ю. П. Чукова, "Введение в квантовую термодинамику необратимых изотермических процессов,” Москва, Россия: Мегаполис, 2018 (Yu. P. Chukova, "Introduction to quantum thermodynamics of nonequilibrium isothermal processes,” Moscow, Russia: Megapolis, 2018.) 